\title{
Helping Moms Learn Online: Leveraging Mobile Technology and Cloud Computing for Maternal Health
}

\author{
Hai Zhang ${ }^{1}$ Ruixue $\mathrm{Xiao}^{2}$ \\ ${ }^{1}$ Hai Zhang, School of Media, Northeast Normal University, Jingyue Street 2555, Changchun, Jilin, P.R. China \\ ${ }^{2}$ Ruixue Xiao, School of Computer Science and Information Technology, Northeast Normal University, Jingyue Street 2555, \\ Changchun, Jilin, P.R. China
}

\section{Abstract}

Together with an explosive growth of the mobile application and emerging of cloud computing concept, this paper proposes a mobile learning framework for maternal health. The framework integrates governments, kindergartens, schools, hospital sand users into a learning ecology, which can create better learning environment for pregnant women. Most importantly, this paper help readers have an overview of the framework including the definition, architecture, and terminal design. The service structure, function module, and execution flow are presented. In addition, the limitation and the future research directions of the framework are discussed.

Keywords: mobile learning, maternal health, clouding computing

Received on 20 January 2014, accepted on 19 June 2014, published on 09 September 2014

Copyright $\odot 2014$ Hai Zhang and 'Ruixue Xiao, licensed to ICST. This is an open access article distributed under the terms of the Creative Commons Attribution licence (http://creativecommons.org/licenses/by/3.0/), which permits unlimited use, distribution and reproduction in any medium so long as the original work is properly cited.

doi: $10.4108 /$ fiee.1.1.e3

\section{Introduction: background and problem analysis}

\subsection{New opportunities: from informal learning to seamless learning}

Previous research has suggested that formal schooling, further education, and informal learning are the three basic modes of adult learning [1][2]. As informal learning is more widespread than many people realize, it is more important than formal systematic learning [3][4].

Compared with formal learning or training, informal learning occurs in broader settings with overt formal purpose [5]. Informal learning happens throughout people's lives in a highly personalized manner based on their individual needs, learning styles, and personal experiences [6]. It includes learning resulting from daily life activities related to work, family, or leisure [7]. It focuses mainly on learner-centered, self-directed activities, often mediated within a social context [8].
Moreover, informal learning provides an experiential base and motivation for further activity and subsequent learning [9]. According to Tough [10], informal learning occurs through deliberate efforts to gain knowledge, skills, and new understanding. Livingstone [11] points out that informal learning can be defined as "any activity involving the pursuit of understanding, knowledge or skill which occurs outside the curricula of educational institutions, or the courses or workshops offered by educational or social agencies" (p. 50).

Since in the digital age, mobile technology such as smartphone and iPad present new opportunities to provide another important infrastructure for informal learning. In this infrastructure, informal learning and other forms of learning constitute a seamless learning space. As a result, informal learning increasingly forms an integral part of lifelong learning and covers many aspects of people's life. Vavoula and colleagues [12] offer a clear typology to classify the types of informal learning based on learning objectives and learning process. Figure 1 illustrates the classification of informal learning. If the learning opportunity presents itself, and both the goals and processes of learning are not explicitly defined by the learner in advance, then the technology used to support the learning will play a more important role with more flexibility. 


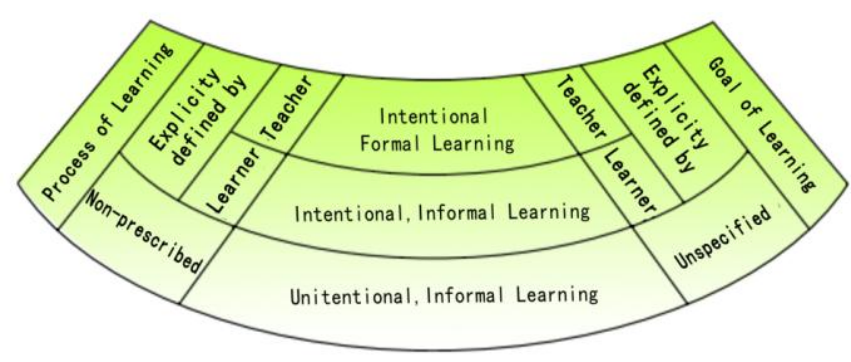

Figure 1. Typology of Informal Learning reproduced from Vavoula et al (2005)(As the shadows deepened, the impact of technology increased)

According to Horizon Reports (2004-2012), the most mentioned up-and-coming learning technologies include mobile learning, augmented reality, and game-based learning. The challenge educators face is how to use technology to bridge formal and informal learning. Chan [13] postulates the notion of seamless learning as learners' experience with a continuity of learning across a combination of locations, times, technologies, or social settings. As personal, portable, wirelessly networked technologies become ubiquitous in our lives, people enter a new era in the evolution of technology-enhanced learning where learning projects can be accessed on multiple devices, flow across boundaries between formal and informal settings, and continue over life transitions such as school to university and workplace [14]. To sum up, seamless learning is a bridge of physical and digital learning, personal and social learning, and informal and formal learning, which can support learners as they construct and reconstruct their own knowledge [15][16].

\subsection{Use of Mobile technologies in health care}

Wireless technologies have been growing pervasively in various applications. But many issues still must be resolved regarding wireless requirements for supporting health care services. These issues include reliable access and transmission of medical information, location management, and support for patient mobility [17][18]. The latest generation of smartphone and iPad features powerful onboard computing capability, capacious memories, large screens, and open operating systems that encourage application development [19]. These devices increasingly are replacing desktop and laptop computers. In the meantime, a gradual shift in the focus of smartphone and iPad has taken place in many felids.

As one of obstacles for health care service, medical workers and patients' available time is always out of sync. Promising mobile networks enable the deployment of new advanced services, facilitating the development of emerging services in the electronic health care area. Thanks to mobile technology, people can get health services anytime from any location [20]. Such technology also can help medical professionals complete their work safely and efficiently . For example, doctors can get patients' records or the latest medical reports by using Multimedia Messaging Service on a mobile phone [21]. Patients' real-time heart rate variability can be monitored by wireless technology.

In daily routines, hospital diagnosis requires a complex process. Patients must make reservations in advance and follow the pre-examination instructions issued by their doctor. However, people often ignore the instructions or fail to read certain directions properly. Mobile technology can support the registration process and help ensure that patients receive, read, and follow pre-examination instructions. In this way, one-stop service can make health services more efficient and humane.

In summary, mobile technology has three main applications in health care: record-keeping, communication, and diagnosis. While with the development of informal learning, health learning supported by mobile technology is a promising field which integrates individuals, communities, hospitals, and mass media into a learning ecosystem.

\subsection{Mobile learning for pregnancy health}

Researchers have thoroughly explored the potential and role of technology-enhanced medical education and consider it as an equally effective and useful supplement to traditional methods (Cook et al. 2008; Harden 2006; Wutoh et al. 2004 ). More and more attention is being paid to the role of mobile learning for educating medical professionals [22][23][24].

Without doubt, children are the touchstone of a healthy and sustainable society; the way a culture or society treats its youngest members has a significant influence on how it will grow, prosper, and be viewed by others. However, not all children are raised by parents who can comfort, nurture, and challenge them appropriately. Carneiro [25] points out that maternal education and home environments influence the development of children. For example, mothers influence the timing and frequency of interactions with providers; the health behaviors of mothers and their children are closely related [26]. Therefore, pregnant women should be given more learning resources and convenient opportunities to learn how to take care of the children.

However, pregnant women are usually spontaneous learners with no specified learning objective or prescribed learning procedure They have no idea about what and how to learn, while each person has different needs in accordance with specific conditions. To meet this need, informal learning seems like a good solution. Mobile technology can support fragmented learning, enable learners to learn anything they want - anytime, anywhere. Network operators also can cooperate with hospitals to provide services and resources that make learning more flexible and convenient. 


\section{Development of a theoretical framework of a knowledge spiral-based learner development ecosystem}

In this paper, the theoretical framework of a learner development ecosystem is developed from the work of Zhang and Maesako [27], which was originally based on the theory of ecology of human development of Bronfenbrenner [28].

As illustrated in Fig. 2, the pregnant woman and associated learners (such as the father and other family members) are at the center of the nested structure. By using tools such as smartphones, iPads, laptops, and desktop computers, learners can interact with the environment through mediated activities. The tools can be divided into software and hardware.

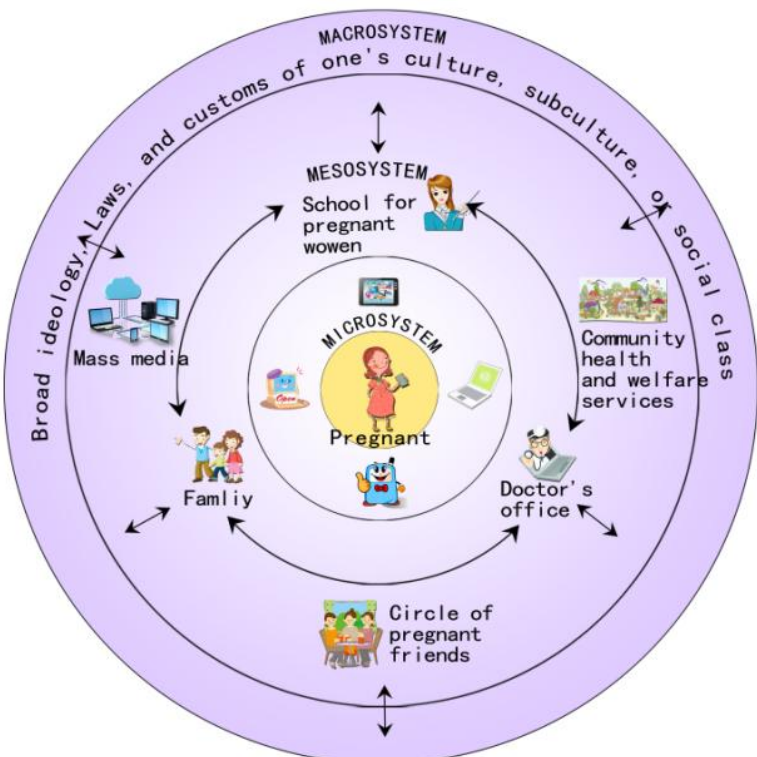

Figure 2. Model of ecosystem of pregnant learner development

The micro-system next to the tool system is a field in which the learner can gain experience by direct involvement. This field contains the pregnant women school, family, and hospital. Pregnant women can acquire parental knowledge by directly interacting with their family, teachers, and doctors. Formal and intentional learning often occur in these situations.

The meso-system comprises the interrelations among two or more settings in which the learner is active. For example, pregnant learners can get useful information from television, websites, or microblogs. They can communicate with fellow learners and share experience in online communities. In addition, the community can also provide health and welfare services. These online and offline activities use the ways of informal learning to make learning, life and work link together for pregnant women. Information and communication technology play an important role in such environments as well.

On a higher level, the macro-system encompasses a broad ideology, laws, customs of one's culture, and social contexts. The learner's development also can be analyzed in view of a long history.

This framework describes a more comprehensive learning ecosystem for the pregnant women than theorists typically envision. Moreover, technical support plays an important role in informal learning for pregnant women. It must fit with in enterprise technical architecture guidelines, such as platforms and databases. Educators should design more resources so that pregnant women can get appropriate information.

\section{Development of China's Maternal and Child Health Note}

The Chinese government has established a Maternal and Child Health Record and electronic record-keeping system. In this way, government must guarantee that the integrity, confidentiality, and availability of electronic health information that they collect, maintain, use, and transmit is protected. However, the main function of the record is recording instead of guidance. As things stand, Chinese pregnant women do not have enough knowledge of maternal and child health, due to their lack of education and insufficient publicity from medical facilities. Therefore, some pregnant women can not fully understand the Note's contents and significance. Also, they often lack knowledge of health management and family planning capability.

In order to help pregnant women acquire more parenting knowledge,this paper proposes a framework of Maternal and Child Health Note and technological path to carry it out. In addition to the function of recording, the framework integrates governments, hospitals, kindergartens and schools into a community, Pregnant women who participate in the community will promote each person learning and they can share new knowledge.

The framework contains five key nodes including governments, kindergartens, schools, hospitals and users. Local governments are responsible for distribution and management of the Note, as well as providing financial support for the other four nodes..

Hospitals play a significant role in the stages of pregnancy and nursing, such as pregnancy testing, delivery, and vaccination. Hospitals record health information on electronic Maternal and Child Health Note.. including diagnosis logging, prescription records, and vaccination. These records form a database of personal health information, which provides reference when emergency or disaster occurs.

During kindergarten and schools, a medical certificate is required for enrollment. Also, schools need to understand students' health situation by using information contained in the Note, such as family history, chronic diseases, and infectious diseases.

Pregnant women and children are the biggest beneficiaries of Maternal and Child Health Note. Pregnant women must submit an application to create an electronic record in the database, which will go with their children 
for life. Hospitals, kindergartens and schools could access to this database when the health information is needed. Pregnant women and children can use the services in a more transparent health care ecosystem by breaking the barriers of different institutions.

The most outstanding features of this framework are unity and connectivity. A healthy environment becomes an organic system instead of isolated elements. All institutions use a unified database, so that information is more accurate and comprehensive reflects a person's entire life. However, in order to implement this framework, one of the most important thing is to construct a cloud-based system with an appropriate architecture and storage space for each individual's health data.
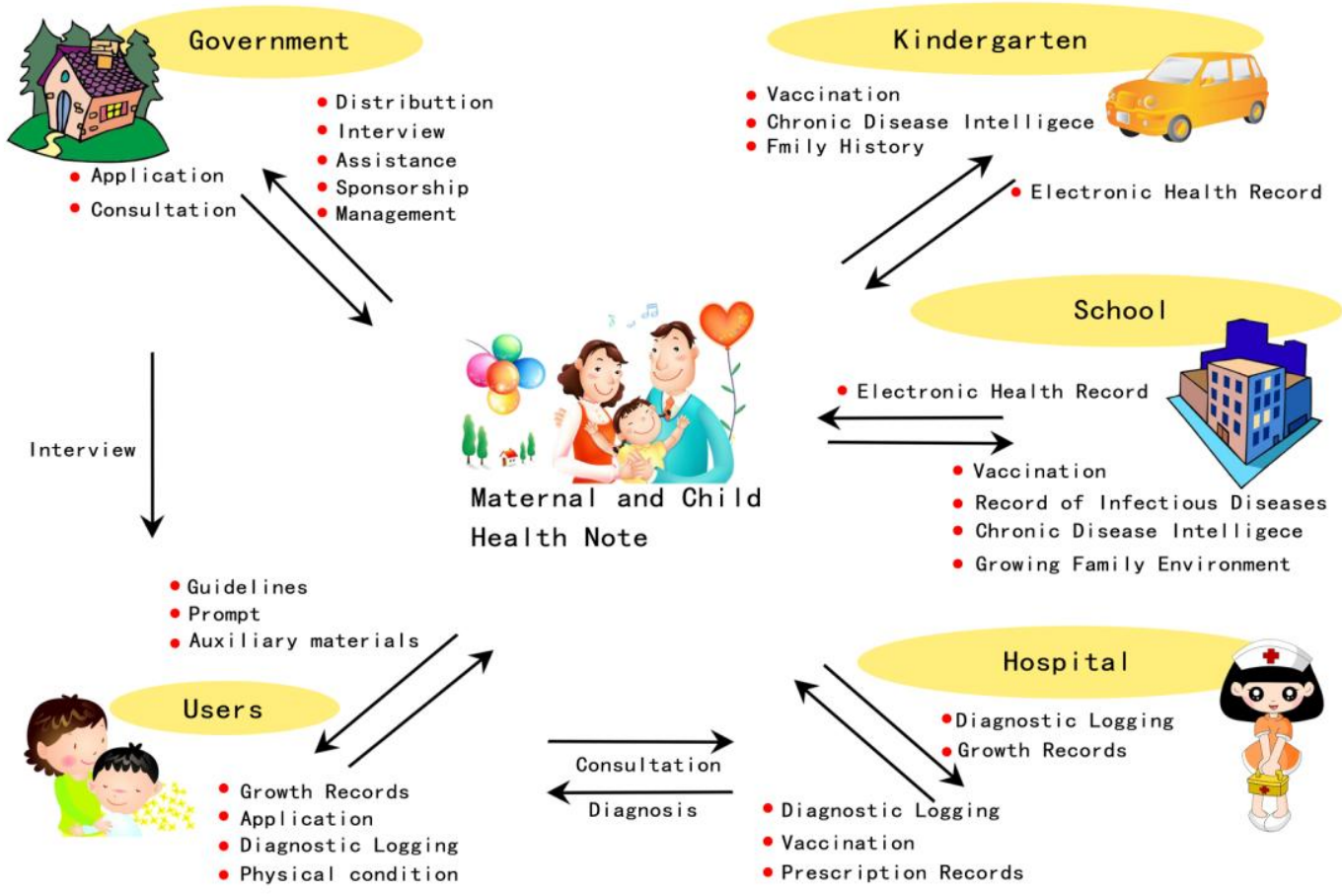

Figure 3. Framework of Maternal and Child Health Note

\section{Development of e-learning system architecture based on cloud computing}

\subsection{Informal learning based on cloud computing}

Brodo [29]suggested that the e-learning ecosystem is for the next generation, however, the current models of e-learning ecosystems lack the support of underlying infrastructures. The cloud computing, which was developed in late 2007, currently emerges as an advanced technology due to its abilities to offer flexible dynamic IT infrastructures, QoS(Quality of Servic) guaranteed computing environments and configurable software services [30]. The advantages of cloud computing is cost saving, flexibility, and accessibility [31][32]. Ouf [33] has presented an innovative e-learning ecosystem based on cloud computing. Masud [34] describes the architecture of cloud computing platform by combining the features of e-learning. This paper intends to create a cloud-based one-stop solution which must be flexible and integrate system framework, terminal design and functional modules together.

\subsection{Architecture}

This paper presents a web-based informal learning system that utilizes various devices available in cloud, such as smartphone, iPad, PDA. The main components of the system are illustrated in Figure 4.

Four major sections are organized to support online learning based on cloud computing. The first section is terminal devices connected to users, supporting input and output. The second section is Network operators, which need to know the network status not only from the network point of view, but also from a service perspective. In addition, providing multimedia services and network resources are also their responsibility. With the converging of fixed network, mobile and IP networks, it is more flexible in the place and manner of access applications for end users. All the communication information summarized by Network operators are transmitted to the Internet service providers, and then be delivered to Application servers. In the clouds, cloud controllers process the requests to provide mobile users with the corresponding cloud services [35]. 


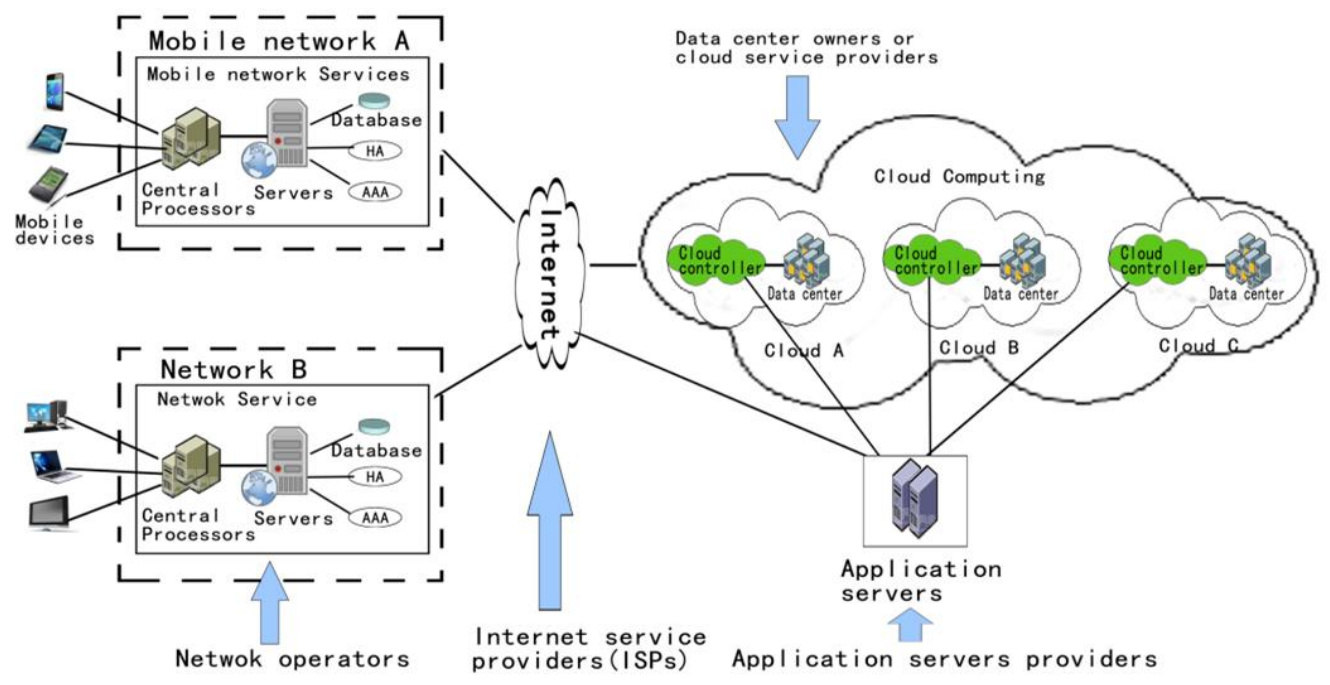

Figure 4. Cloud computing architecture

\subsection{Terminal devices}

Terminal equipment is defined as two levels of software and hardware [36].The hardware includes smartphone, iPad, PDA, PC, IPTV and so on. Wearable devices, such as Google Glass, have also been included in Users can obtain services directly through registration without having to download the client software. The functions of the terminal integrate services of social networking, online learning systems, medical systems and portals etc. The terminal interface provides users with the possibility of accessible learning., so that texts, pictures, videos and other data can be easily obtained, making learning more flexible and personalized. Figure 5 illustrates the design of the mobile terminals.
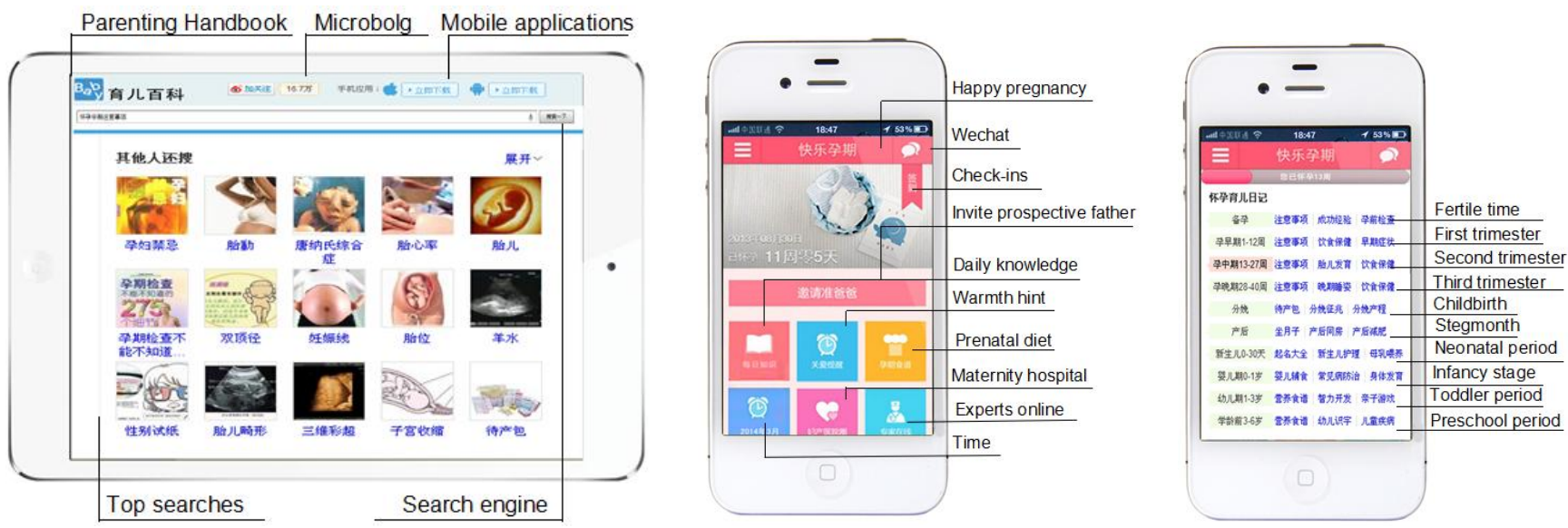

Figure 5. Terminal design

\section{Development of a framework of Maternal and Child Health Learning System}

\subsection{Service structure}

The Maternal and Child Heath learning system provides users with various services at pre-pregnancy, pregnancy and parenting stages. Services mainly related to online appointment, physical examination items, medical feedback etc. As listed in Table 1. 
For instance, during pregnancy (38-45 days), pregnant women need to undergo a color Doppler ultrasound examination to rule out the possibility of ectopic pregnancy. Since the system can calculate pregnant time automatically according to the Maternal and Child Health Note stored in the database, in the first 35 days, the system will push information to users, reminding the check needs to be done, and provide a detailed description of precautions. After that, users can get touch with their doctors and make appointments online. Then they can complete the inspection process with the help of intelligent medical assistant. Their doctors will put the check results into the database, and provide feedback to the system terminals. Moreover, dynamically updated database of medical knowledge and the check results will be automatically matched through evaluation, then personalized medical information would be pushed to users. Furthermore, the wearable devices can also be integrated into the system. For example, smart watches can timely monitor pregnant women's weight, blood pressure, heart rate and the number of uterine contraction. Monitoring data is processed and analyzed in the clouds, which is transparent to hospitals. Analysis reports will be sent to users via intelligent terminals, so that pregnant women can understand their physical condition in real time.

\begin{tabular}{|l|c|c|c|}
\hline \multicolumn{2}{|c|}{ Time } & Check Items & \multicolumn{1}{|c|}{ Services } \\
\hline Prestation & Before pregnancy & Routine examination & \multirow{2}{*}{ Remind of the check time } \\
\cline { 2 - 3 } & 38-45 days & color Doppler ultrasound; Blood & \multirow{2}{*}{ Online appointment } \\
\cline { 2 - 3 } & progesterone & \multirow{2}{*}{ Demonstrate the inspection } \\
process
\end{tabular}

Table 1. Service structure

\subsection{Functional design}

The Maternal and Child Health Learning System not only provides health care knowledge for pregnant women, but also establishes high-efficiency learning environments As pregnant women being in a complicated ecosystem, the learning process is complex, diverse and non-linear. On the one hand, they have no sense on what and how to learn, on the other hand, there are so many factors will influence their learning needs and learning effects. For example, pregnant women with heart disease will more concerned with the effect of medicine used on the foetus; Pregnant people in different economic conditions have different requirement for the recommendation of baby-care products; Specially, baby boys and baby girls care knowledge should also be personalized postal. In order to meet users' various needs, this system has exactly open and dynamic characteristics. As an practical application of cloud computing, comprehensive data on pregnant women should be tracked, and a comprehensive service platform with scientific analysis model should be equipped. Thereby, in addition to logging functionality, evaluation, interaction and synthetic analysis are also indispensable. As shown in figure 6 : 


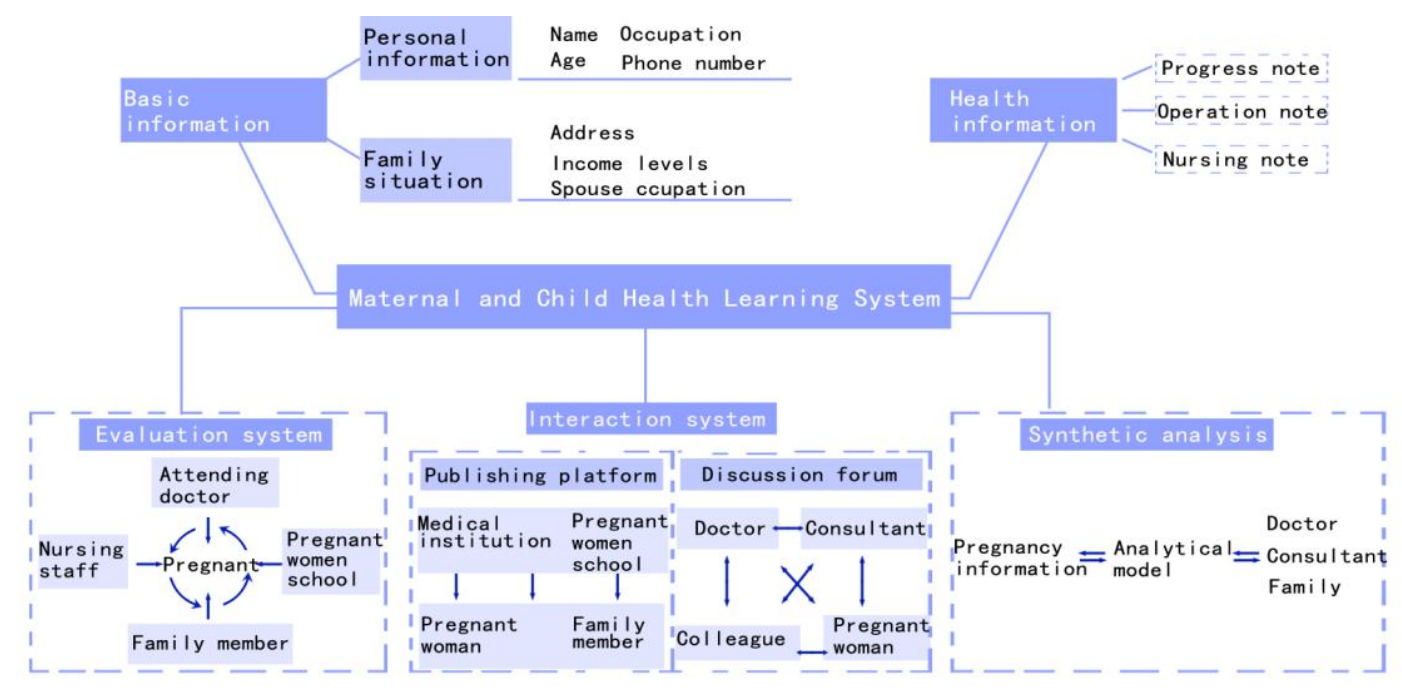

Figure 6. Functional design

(i) Basic information module

Basic information module is divided into personal information such as name, age, occupation and education background, as well as family status including address, income levels, spouse occupation etc. The discrepancies in age, occupation and family situation play an important role in the physical and mental health condition of the pregnant women. Thus these information can be used as reference for comprehensive analysis.

(ii) Health information module

Pregnant women's health information is composed of progress notes, operation notes and nursing notes, which is the core content of Maternal and Child Health Note.

(iii) Evaluation system module

Evaluation system module is used to record and evaluate the health of pregnant women by people who have close contact with them during the gestation. Attending physicians and nursing staffs focus on maternal health indicators' monitoring and evaluation. Teachers in pregnant women school usually play the roles of consultants by providing systematic knowledge on maternal and child health, so they can evaluate pregnant women's learning status. In addition, family members have more accurate evaluation of maternal health, because they have detailed understanding of pregnant women's dietary habit, exercise condition and psychological feature. These people mentioned above make up a four-in-one health evaluation module, providing full range of health protections for pregnant women.

(iv) Interaction system module

Hospitals, pregnant women schools, family members and pregnant women themselves can interact through this module with the purpose of helping pregnant women raise their body and maintain good state.. The interaction system module consists of two main parts of the publishing platform and discussion forum. Hospitals and schools can launch research to pregnant women and their family members, in order to hold the health circumstances timely and effectively. Discussion forum is created for users' realtime conversation, so that they can invite others to talk, research, discuss and solve problems in a flexible way. In view of the cloud computing platform's powerful interactive capabilities, users can access through smartphone, laptop and any other terminals at any time, and all records will be temporarily stored in the cloud storage server waiting to be called up on demand.

(v) Synthetic analysis module

Synthetic analysis module can generate analysis reports on the basis of a lot of maternal health analysis model stored in advance, according to pregnancy information and four-in-one health evaluation. Through the accurate analysis of maternal daily records, both phased physical health and mental health condition can get immediate feedback, and all of these are transparent to users. Also, the analysis report is one of the main reference of resource-push mechanism.

\subsection{System flow chart}

Figure 7 shows the embodiment of Maternal and Child Health Learning System, including data acquisition, analysis and output. This system is built on an existing parenting knowledge database, which involves summary of frequently asked questions, meanings of detection indicators, matching of symptoms and treatment programs and so on. The database is open, dynamic, continuously updated and expanded based on cloud ensuring the storage space and operating efficiency.

System's initial data is extracted from the Maternal and Health Note. Governments, hospitals, kindergartens, and schools' data are gathered here, classified by the individual as a unit for storage. In adaption, users' access information and data updated by wearable devices also belong to a data source. The second step is to summarize, classify and extract data into normal items, abnormal items, items need to be noticed and items which users want to know, then extract corresponding content from the knowledge database and push them to users. Types of resources can be divided 
into pregnancy, infancy and early childhood, types of services are also various at different stages.

The resources during pregnancy are distributed in preparing, pregnancy check, delivery, pharmacy, nutrition and so on. At beginning, the father and mother are all newcomers need to learn from scratch. They have no idea on how to bathe the baby, change diapers, massage the baby, or even how to hold the baby. And of course they would not know how to take care of the baby when it's sick. Most traditional parenting tutorial is linear text, while the video tutorials based on the system makes the learning process a lot easier and more graphical. Parents begin to focus on the child's physical training from its early childhood and each child has its own unique characteristics and special needs. In addition to providing parental knowledge, this system designs a social networking platform to support parents sharing their experiences and emotion. Moreover, the system also supports terminal access to the system library. Users can not only search, store and download data, but also consult the smart medical experts through forums, comments, etc.

All in all, this framework is a dynamic system built on cloud computing, integrating various elements of pregnant women's learning ecosystem together. The services lasted from protestation to parenting, supporting personalized learning through a variety of terminals any time at any place. The system is also scalable and able to support lifelong learning.

\section{Conclusion}

This paper proposes a framework of pregnant women's development ecosystem for the purpose of designing an information infrastructure for informal learning. Depending on the framework, an encompassing Maternal and Child Health Note is been constructed through the integration of the various elements in the ecosystem. Since this framework is based on cloud computing, each section saves data to the clouds through different terminals and can withdraw and apply data at any time. for the purpose of ensuring medical process's fluency and accuracy . Most importantly, the system integrates varieties of resources and opportunities for pregnant women's learning. Embodied in the following points:

(i) Most institutions which have effects on the health of pregnant women have been formed into a community..And, transparent data in the clouds eliminates the barriers between the various institutions.

(ii) Health data stored in the clouds can be seen as people's healthy growth profile. This will serve as an important component of smart society.

(iii) Hospitals, communities and medias can play as providers offering personalized learning services for pregnant women.

(iv) Resources can be seamlessly adapted between various devices, which guarantee pregnant women's informal learning. As one of the most important ways of lifelong learning, informal learning is more concerned about the individual's needs and experience. Besides, huge storage and data processing capabilities based on cloud make informal learning environment more intelligent.

(v) This framework is a combination of mobile health and mobile learning. However, both health and education issues are complex fields. As dissipation theory emphasizes the dynamic and openness of a complex system, establishing relationship between various elements of social-ecological system and promote its virtuous cycle can help people live better.

\section{Limitation and future research direction}

Considering the variety of factors, learning is a highly contextualized and personalized dynamic process. The current framework refinement process will encounter a variety of practical problems. In particular, maternal health care acquires for multi-joint collaboration between families, hospitals, communities and mass medias. Governments' organization and coordination is essential as well. Currently, we have got agreement with a number of institutions and our next goal is the development of a practical prototype and its verification for the purpose of revising and developing our framework.

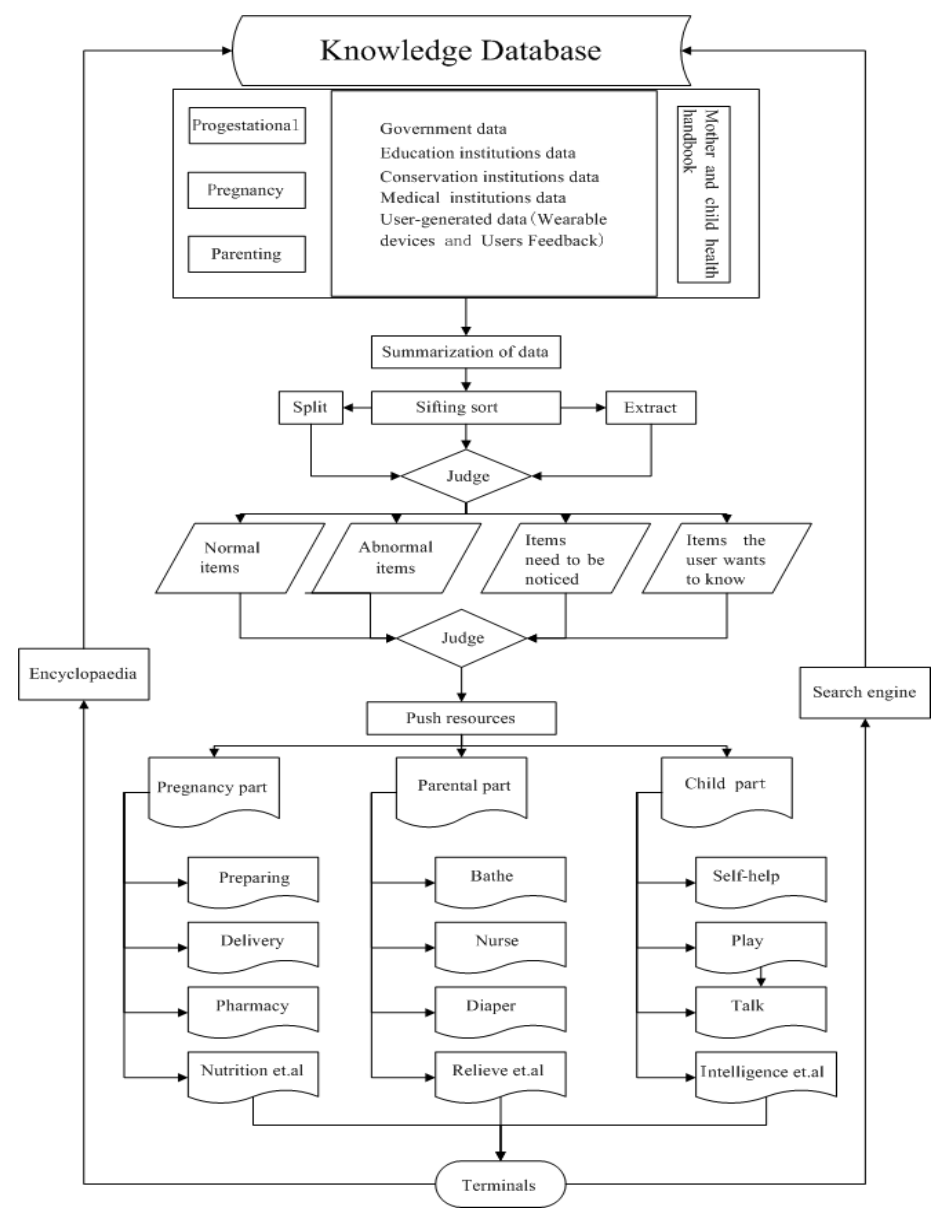

Figure 7. System flow chart 


\section{Acknowledgements}

This work was supported by the National Social Science Foundation of China(12CXW020), the Humanities and Social Science Foundation, Ministry of Education of China(11YJC880159), the Scientific Research Foundation for the Returned Overseas Chinese Scholars, Ministry of Education of China, the team project of Philosophy and Social Sciences of Northeast Normal University(12QN043). The authors would like to thank Jeff South for his valuable support to the completion of this paper.

\section{References}

[1] Coombs, P. (1985). The world educational crisis: The view from the eighties. New York:Oxford University Press.

[2] Selman, G., \& Dampier, P. (1991). The foundations of adult education in Canada.Toronto: Thompson Educational Publishing.

[3] Boud, D., \& Middleton, H. (2003). Learning from others at work: communities of practice and informal learning. Journal of Workplace Learning, 15(5), 194-202.

[4] Clough, G., JONES, A., McAndrew, P., \& Scanlon, E. (2009). Informal learning evidence in online communities of mobile device enthusiasts. Mobile Learning, 99.

[5] Eraut*, M. (2004). Informal learning in the workplace. Studies in continuing education, 26(2), 247-273.

[6] Bull, G., Thompson, A., Searson, M., Garofalo, J., Park, J., Young, C., \& Lee, J. (2008).

[7] Descy, P., \& Tessaring, M. (2001). Training and Learning for Competence: Second Report on Vocational Training Research in Europe. Executive Summary. CEDEFOP Reference Series. CEDEFOP, PO Box 22427, Thessaloniki, GR-55102 Greece.

[8] Marsick, V. J., \& Watkins, K. E. (2001). Informal and incidental learning. New directions for adult and continuing education, 2001(89), 25-34.

[9] National Science Foundation. (2006). Informal science education program solicitation(NSF 06-520).

[10] Tough, A. (1979). The adult's learning projects: A fresh approach to theory and practice in Adult Learning. Toronto: OISE Press.

[11] Livingstone, D. (1999). Exploring the icebergs of adult learning: Findings of the first Canadian survey of informal learning practices. CJSAE 13 (2), 49-72.

[12] Vavoula, G. N., Lonsdale, P., Scanlon, E., Sharples, M., Jones, A., \& Hardy, P. (2005). D. 33.2 Report on empirical work with mobile learning \& literature on mobile learning in science. MELISSA JEIRP Project Deliverable 33.2 for Kaleidoscope European Network of Excellence.

[13] Chan, T.-W., Roschelle, J., Hsi, S., Kinshuk, Sharples, M., Brown, T. et al. (2006). One-to-one technology-enhanced learning: an opportunity for global research collaboration. Research and Practice in Technology-Enhanced Learning, 1, $1,3-29$.

[14] Looi, C. K., Seow, P., Zhang, B., So, H. J., Chen, W., \& Wong, L. H. (2010). Leveraging mobile technology for sustainable seamless learning: a research agenda. British Journal of Educational Technology, 41(2), 154-169.

[15] Wong, L.-H., \& Looi, C.-K. (2011). What seams do we remove in mobile assisted seamless learning? A critical review of the literature. Computers \& Education, 57(4), 2364-2381.
[16] Wong, L.-H. (2012). A learner-centric view of mobile seamless learning. British Journal of Educational Technology, 43(1), E19-E23.

[17] Kafeza, E., Chiu, D. K., Cheung, S. C., \& Kafeza, M. (2004). Alerts in mobile healthcare applications: requirements and pilot study. Information Technology in Biomedicine, IEEE Transactions on, 8(2), 173-181.

[18] Wu, I. L., Li, J. Y., \& Fu, C. Y. (2011). The adoption of mobile healthcare by hospital's professionals: an integrative perspective. Decision Support Systems, 51(3), 587-596.

[19] Komnakos, D., Vouyioukas, D., Maglogiannis, I., \& Constantinou, P. (2008). Performance evaluation of an enhanced uplink $3.5 \mathrm{G}$ system for mobile healthcare applications. International journal of telemedicine and applications, 2008.

[20] Istepanian, R., Laxminarayan, S., \& Pattichis, C. S. (2006). M-health: emerging mobile health systems. M-Health: Emerging Mobile Health Systems, Edited by R. Istepanian, S. Laxminarayan, and CS Pattichis. 2006 XXX, 624 p. 182 illus. 0-387-26558-9. Berlin: Springer, 2006., 1.

[21] Oztekin, A., Pajouh, F. M., Delen, D., \& Swim, L. K. (2010). An RFID network design methodology for asset tracking in healthcare. Decision Support Systems, 49(1), 100-109.

[22] Istepanian, R. S., Jovanov, E., \& Zhang, Y. T. (2004). Guest editorial introduction to the special section on m-health: Beyond seamless mobility and global wireless health-care connectivity. Information Technology in Biomedicine, IEEE Transactions on, 8(4), 405-414.

[23] Wu, J. H., Wang, S. C., \& Lin, L. M. (2007). Mobile computing acceptance factors in the healthcare industry: A structural equation model. International journal of medical informatics, 76(1), 66-77.

[24] Boulos, M. N., Wheeler, S., Tavares, C., \& Jones, R. (2011). How smartphones are changing the face of mobile and participatory healthcare: an overview, with example from eCAALYX. Biomedical engineering online, 10(1), 24.

[25] Coulby, C., Hennessey, S., Davies, N., \& Fuller, R. (2011). The use of mobile technology for work- based assessment: the student experience. British Journal of Educational Technology, 42(2), 251-265.

[26] Irby, D. (2011). Educating physicians for the future: Carnegie's calls for reform. Medical Teacher, 33(7), 547550.

[27] Sandars, J., \& Morrison, C. (2007). What is the Net Generation? The challenge for future medical education. Medical teacher, 29(2-3), 85-88.

[28] Carneiro, P., Meghir, C., \& Parey, M. (2013). Maternal education, home environments, and the development of children and adolescents. Journal of the European Economic Association, 11(s1), 123-160.

[29] Minkovitz, C. S., Strobino, D., Scharfstein, D., Hou, W., Miller, T., Mistry, K. B., \& Swartz, K. (2005). Maternal depressive symptoms and children's receipt of health care in the first 3 years of life. Pediatrics, 115(2), 306-314.

[30] Zhang, H., \& Maesako, T. (2009). A framework of learner development ecosystem for designing a ubiquitous educational informational infrastructure. Journal of Software, 4(2), 124-131.

[31] Bronfenbrenner, U., \& Bronfenbrenner, U. (2009). The ecology of human development: Experiments by nature and design. Harvard university press.

[32] Brodo, J. A. (2002), Today's Ecosystem of e-learning,Vice President, Marketing.

[33] Wang, L., Tao, J., Kunze, M., Castellanos, A. C., Kramer, D., \& Karl, W. (2008, September). Scientific cloud computing: Early definition and experience. In High 
Performance Computing and Communications, 2008. HPCC'08. 10th IEEE International Conference on (pp. 825830). IEEE

[34] Dong, B., Zheng, Q., Yang, J., Li, H., \& Qiao, M. (2009, July). An e-learning ecosystem based on cloud computing infrastructure. In Advanced Learning Technologies, 2009. ICALT 2009. Ninth IEEE International Conference on(pp. 125-127). IEEE.

[35] Rao, N. M., Sasidhar, C., \& Kumar, V. S. (2012). Cloud computing through mobile-learning. arXiv preprint arXiv:1204.1594.

[36] Kalakota, R., \& Robinson, M. (2003). Electronic commerce (pp. 628-634). John Wiley and Sons Ltd..
[37] Ouf, S., Nasr, M., \& Helmy, Y. (2010, December). An enhanced e-learning ecosystem based on an integration between cloud computing and Web2. 0. In Signal Processing and Information Technology (ISSPIT), 2010 IEEE International Symposium on (pp. 48-55). IEEE.

[38] Masud, M. A. H., \& Huang, X. (2012). An e-learning system architecture based on cloud computing. system, 10(11).

[39] Dinh, H. T., Lee, C., Niyato, D., \& Wang, P. (2011). A survey of mobile cloud computing: architecture, applications, and approaches. Wireless Communications and Mobile Co 